\title{
PREDATION ON CERCOPIDS AND MATERIAL USE OF THE SPITTLE IN APHID-TENT CONSTRUCTION BY PRAIRIE ANTS*
}

\author{
By Gregg Henderson, George D. Hoffman \\ AND ROBERT L. JEANNE \\ Department of Entomology, University of Wisconsin-Madison, \\ Madison, Wisconsin 53706
}

\section{INTRODUCTION}

In southern Wisconsin, Formica montana Emery, and the meadow spittlebug, Philaenus spumarius (L.), share the same habitats, occurring together on plants in prairies and open fields. Very little is known about the interactions of cercopids and ants. One of the purposes of this study was to determine if ants are predators of immature spittlebugs.

Cercopid (or spittlebug) nymphs appear to have few predators. In the nymphal stage, cercopids excrete a watery mixture which includes glycoproteins from the Malpighian tubules, the glands of Batelli, and the intestinal tract (Guilbeau, 1908; Licent, 1912; Cecil, 1930). Once air is pumped into it, this mixture forms the characteristic covering of spittle in which cercopids complete development (Weaver and King, 1954). The spittle covering is believed to protect cercopids from predators and parasites and from unfavorable microclimate conditions (Buckton, 1890; Jones, 1929; Whittaker, 1970). In the one study to test the hypothesis that spittle protects against predation, the significant finding was that more dead spittlebugs placed in the field were missing after $48 \mathrm{~h}$ if spittle was not applied to their dead bodies than if spittle was applied (Whittaker, 1970). The predators of the "spittleless" cercopids were not identified.

A second purpose of this research was to document prairie ants' use of cercopid spittle in aphid-tent construction. F. montana tends honeydew-producing aphids for food (Henderson, et al., 1989). Aphid-tending $F$. montana aggressively attack most predators of honeydew-producing Homoptera, and they construct aphid-tents

*Manuscript received by the editor November 17, 1989. 
(i.e., housing on plants at the site of aphid feeding). Aphid-tents are built specifically to protect aphids and membracids (Wheeler, 1910; Jones, 1929; Way, 1963; Carroll and Janzen, 1973; McEvoy, 1977) and may even increase honeydew production (Stopes and Hewitt, 1909).

Nothing has been noted in the literature about how aphid-tents made of soil and thatch hold together when suspended from plant stems. What is the "glue" for aphid-tent construction in groundnesting ants? We made observations of aphid-tent construction by prairie ants and attempted to identify the "glue" used to hold soil and thatch tents together. We present evidence that prairie ants utilize spittle for the construction of aphid-tents.

\section{The CERCOPID}

Philaenus spumarius, the meadow spittlebug, is a univoltine species, hatching in early spring, developing through five instars and molting to the adult in early summer (Weaver and King, 1954). It is common to Europe and North America, but has been reported from Asia, Africa, Japan, and South America (Hoffman, 1983). Meadow spittlebugs feed exclusively on xylem sap (Wiegert, 1964; Horsfield, 1978) and have a host range of several hundred plant species (Weaver and King, 1954). The concentration of nitrogenous compounds and sugar in xylem sap is extremely low (Pate, 1976, 1980), and necessitates a high feeding rate and the excretion of excess water (Hoffman, 1983). The economic importance of spittlebugs is well known, many host plants suffer from cercopid feeding to some degree (Weaver and King, 1954; Wilson and Dorsey, 1957; Zajac and Wilson, 1984).

\section{Methods}

Field studies. For two foraging seasons (1987 and 1988) the relations of $F$. montana and P. spumarius were studied in plots located in Fitchburg, WI, Madison, WI, and Barneveld, WI. Field surveys were made at least once a week and spittlebug interactions with the prairie ants as well as spittlebug/plant associations were noted.

To determine if prairie ants affect cercopid population numbers, sweep-samples ( 140 sweeps per site in an ' $X$ ' pattern) were taken in June, July and August 1987 in two $25 \times 50 \mathrm{~m}$ plots at Curtis Prairie 
(University of Wisconsin Arboretum, Madison, WI) and cercopid numbers were counted. One plot (site A), containing 27 F. montana nests, was last burned for prairie maintenance in the first week of April 1987. The other plot (site B) was burned in 1986; it contained no $F$. montana nests. We compared adult cercopid numbers in the ant plot (A) versus the "antless" plot (B).

To determine if ants utilize spittle for the construction of aphid tents, a $F$. montana nest was relocated to a plot next to plot B in May 1987. Transfer of the nest ensured that any subsequent interactions between ants, cercopids, and plants, were not the result of long-term habitat modifications provided by the mound itself. In May 1988 we marked (with blue ribbon) 53 curlydock, Rumex crispus (a plant heavily utilized by $F$. montana and the attendant aphid Aphis rumicis L.) located within $6 \mathrm{~m}$ of the transferred nest. On 15 May, 30 May, 7 June, and 15 June, we recorded the number of plants harboring spittlebugs and any signs of aphid tent construction. We compared this spittlebug distribution with the distribution of spittlebugs on 17 marked $R$. crispus located $30 \mathrm{~m}$ from the introduced nest, and far from the next nearest $F$. montana nest. Aphid occupation of curlydock was also noted.

Laboratory studies. To determine if predation on P. spumarius by $F$. montana occurs, we conducted two greenhouse experiments (Walnut Street greenhouses, University of Wisconsin). P. spumarius nymphs were collected from an alfalfa field in Cross Plains, WI, and transferred to broad bean (Vicia fava) in the greenhouse. The spittlebugs readily fed on broad bean and within 15 min formed spittlemasses. In the first week of May 1989, four collections of $F$. montana were made from Cross Plains, WI. In each ant colony queens and eggs were included with workers $(>300$ workers, but varied between collections) and placed along with the mound soil in a screened cage (ca. $45 \times 30 \mathrm{~cm}$ ). Tree Tanglefoot ${ }^{\circledR}$ (The Tanglefoot Co., Grand Rapids, Michigan) was applied to the cage legs to prevent ants from migrating out. Caged ants were supplied with fresh honey and water every other day.

Experiment 1. Do $F$. montana prey on spittlebugs in their spittle? Fourth and fifth instar nymphs were placed on broad bean and allowed to form a spittlemass. Bean plants with 15 recently placed spittlebugs (with spittle) were then set into two cages containing a 
prairie ant colony (one plant per colony). Honey was put on the uppermost leaves of the plant to simulate honeydew and increase ant foraging. Young broad beans also have extrafloral nectaries which attracted ant foragers (Henderson, personal observation). As a control, a "honey-tipped" plant harboring 10 spittlebugs was placed into each of two "antless" cages. After $72 \mathrm{~h}$, treatment and control cercopids were counted and spittlemasses were inspected for soil and thatch materials. We repeated the experiment twice, pooling the results to determine if there was a difference between spittlebug survival in ant cages versus "antless" cages.

Experiment 2. Are living $P$. spumarius preyed on more readily by ants when they are out of spittle than when they are in spittle? In nature, spittlebugs frequently leave their spittle after a molt in order to establish a new mass on a non-lignified portion of the stem (McEvoy 1986, Hoffman and McEvoy 1986). Being between spittlemasses may be a particularly vulnerable period for the spittlebug. For a test, a honey-tipped bean plant was placed into a caged ant colony and ants were allowed to forage. After one-half hour, six fourth or fifth instar nymphs were placed on the plant's stems and covered with spittle collected from captive spittlebugs fed on broad beans (treatment 1), or left without spittle (treatment 2). For the next $10 \mathrm{~min}$, we recorded the number of ant contacts of a spittlebug or spittlemass, number of attacks (e.g., biting, spraying), number of kills (spittlebugs taken from plant and carried into nest) and other ant behavior associated with contacting a spittlebug (e.g., grooming). The order in which the treatments were presented to the colony was randomized, with the second test immediately following the first. Six trials were conducted using new plants each time. A trial was never repeated within $24 \mathrm{~h}$ of the previous trial.

We also compared ant responses toward washed spittlebugs (rinsed in water for several seconds) and unwashed spittlebugs that were removed from a spittlemass. Rinsing had no observable effect on the spittlebugs. Individual spittlebugs were introduced onto a honey-tipped broad bean in the ant cages. Six of each type of spittlebug were placed individually on a broad bean and observed for 10 min or until it was carried away by an ant.

\section{RESUlts}

Field. Spittlebug nymphs were found on goldenrod (Solidago altissima), curlydock (Rumex crispus), thistle spp. (both Canadian [Cir- 
sium arvense $]$ and Prairie [C. discolor $]$ ), and meadow sweet (Spiraea alba).

In every month surveyed cercopid adults were more numerous in the antless plot than in the ant plot (Fig. 1). Five percent of the cercopids collected in the ant plot in June and 5\% from the antless plot in July were nymphs; all others collected were adults. Clearly, sweep samples were effective for collecting adult cercopids only.

Aphid-tents occurred on plant species that harbored spittlebugs listed above. Inside the soil and thatch and sometimes plant seed shelters were housed aphids, or membracids in the case of goldenrod, and their tenders, F. montana (see Fig. 2). Membracids feeding on goldenrod caused wilting of the leaves just above the feeding site. In some cases wilted leaves covered the membracids and reduced the soil load needed for the aphid-tent.

Aphid-tent construction using spittle was observed in the field. On 22 May 1987, F. montana foragers were tending Aphis cardnella Walsh for their honeydew on Canadian thistle (Cirsium arvense) at Barneveld. Several thistles also harbored spittlebug nymphs, and ants $(n=5)$ carried soil and thatch up the plants, placing the materials directly on the spittlemasses. The spittlemass was absorbed by the soil and thatch. The ants tended to place material along the perimeter of a spittlemass, completely surrounding the spittlemass before covering it. Soil and thatch completely surrounded the stem of one of the thistles and ants and aphids were housed inside the abode.

Soil soaked with rainwater was also used for aphid-tents by $F$. montana tending Chaitophorus populicola Thomas on a small quaking aspen in Curtis Prairie. On the morning of $25 \mathrm{July}$, after an evening rain, two aphid-tents were present on the quaking aspen, and aphid numbers were higher inside the tent than outside. It is unlikely that spittle was used here because quaking aspen does not harbor spittlebugs. The tents were loosely constructed and lasted only about a day. By 27 July, both aphid-tents were gone.

Spittlebug nymphs were more abundant on $R$. crispus close to an ant nest (Table 1). Every plant that harbored a spittlebug also harbored aphids. Forty-four percent of the $53 R$. crispus within $6 \mathrm{~m}$ of a nest with spittlemasses also had soil and thatch on them; however, the spittlemasses did not become functioning aphid tents (i.e., the enclosure was not complete and homopterans were not found inside). 


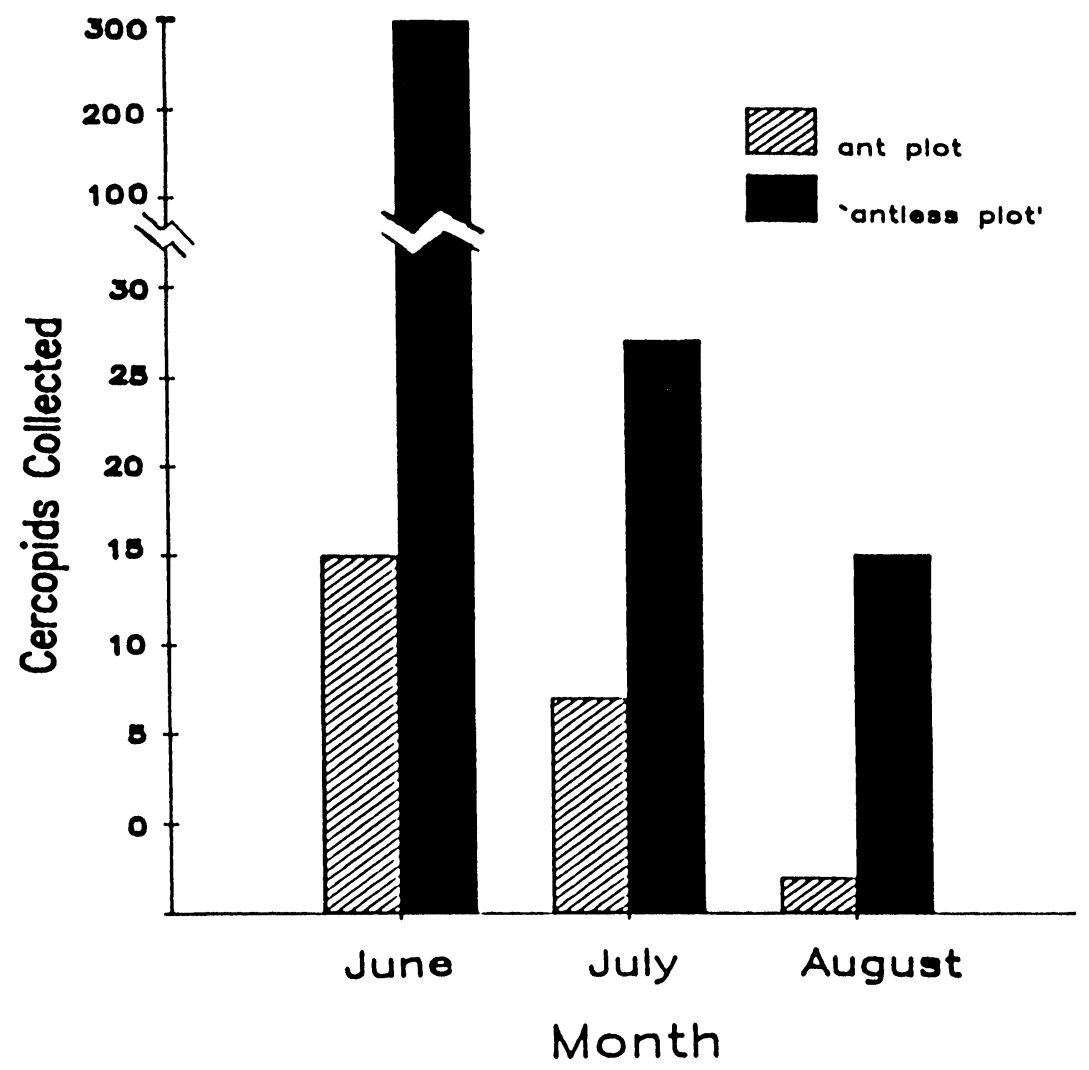

Fig. 1. Comparison of cercopid populations between equal-size plots with and without $F$. montana populations.

Laboratory. In all four tests of spittlebugs in ant cages, signs of ant predation were evident; $25 \%$ of the spittlebugs were missing after 72 h (range; $40 \%$ to $13 \%$ predation), and many spittlemasses were strewn with pieces of soil and thatch. All control spittlebugs remained in their spittlemasses for the $72 \mathrm{~h}$ duration $(0 \%$ missing), and no soil and thatch were found on the spittlemasses. This result means that ants are predators of cercopids despite the spittle. (Note: statistics were not used in comparing the treatment with the control because the control had no variance.)

Spittlemass remnants were partially collapsed by the soil and thatch that absorbed some of its moisture. This also provided ants 


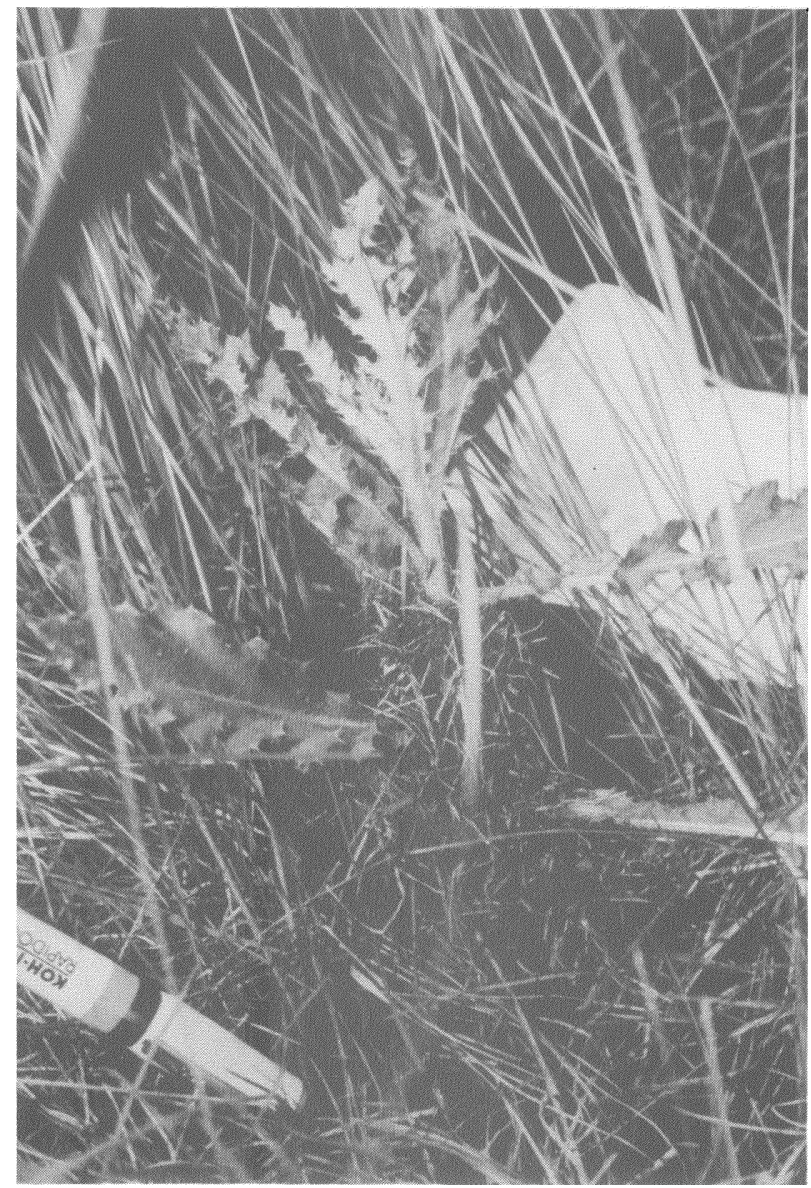

Fig. 2. Aphid-tent built by $F$. montana on Canadian thistle.

with an access route to the spittlebugs. Three ants appeared to take up some of the spittle by ingesting it. Spittle drinking has also been noted in yellowjackets (Akre et al., 1976).

In the 10 min tests, neither spittlebugs devoid of spittle, nor those in spittle were preyed on. Of 103 ant contacts of a cercopid out of spittle, eight resulted in an attack (8\%), and no spittlebugs were carried back to the nest (i.e., no predation). Similarly, of 101 ant contacts of spittlemasses, seven resulted in an attack (7\%), and again, no spittlebugs were carried back to the nest. Ants groomed 
Table 1. The relationship between cercopid numbers, tent-building, and mound distance. The percentage of Rumex crispus plants occupied by spittlebug nymphs and the percentage of those plants showing signs of aphid tent construction in A) a plot next to an ant nest versus B) a plot far from an ant nest.

\begin{tabular}{lccccc}
\hline & \multicolumn{2}{c}{ With Cercopid Nymphs (\%) } & & \multicolumn{2}{c}{ With Tent Building (\%) } \\
\cline { 2 - 3 } \cline { 5 - 6 } Date & Ant Plot & Antless Plot & & Ant Plot & Antless Plot \\
\hline 25 May & 26 & 6 & 0 & 0 \\
30 May & 30 & 6 & 44 & 0 \\
6 June & 13 & 0 & 42 & 0 \\
15 June & 0 & 0 & 0 & 0 \\
\hline
\end{tabular}

their antennae immediately after some contacts with a spittlebug $(n=12)$ or its spittle $(n=22)$, suggesting that contact with the spittle and the spittlebug irritated the ants. It is possible that the "spittless" bugs still had some spittle on their body surfaces. This hypothesis was supported by the washed spittlebug tests.

Four of six $(67 \%)$ washed spittlebugs were taken by ants and carried into the nest within $10 \mathrm{~min}$, whereas one of six (17\%) unwashed spittlebugs were carried away. Not only did ants respond more aggressively to washed spittlebugs, but the thin spittle film on the unwashed cercopids appeared to make it harder for the ants to pull them from the plant stem. The film made the spittlebugs slippery and hard to grab, and perhaps even enhanced the spittlebug's tenacious grip on a plant.

\section{Discussion}

Prairie ants influence meadow spittlebug populations. Part of the ants' control is through predation, but since cercopids sampled by sweeping were mostly adults, it is likely that the ants' aggressiveness influenced emigration and immigration events between the Curtis Prairie sites as well. It is possible that other ant species will prove to be effective cercopid predators in habitats where natural control is desirable.

Spittle provided protection to the cercopids from predatory ants, but the protection was not complete. Prairie ants can place soil and thatch on spittle, and in this way gain access to the soft-bodied nymphs. The behavior of aphid-tent building may have evolved from the more general habit of nest construction (Wheeler 1910; 353). Arboreal ant species such as Oecophylla, Polyrhachis, Crematogaster and Liometopum construct aphid-tents using similar 
architecture and building materials as they use in the nest (e.g., paper carton or nearby leaves) (Wheeler 1910). Likewise, for ground nesting ants, soil and thatch function as both ant nest and aphidtent building materials (Wheeler, 1910; Henderson, personal observations). Spittle helps to glue together the soil and thatch aphid-tents.

Cercopid nymphs were actually present in greater numbers on $R$. crispus near an ant nest than farther away. It is unlikely that ants are influencing the distribution of cercopid nymphs in any positive way given the findings here. One possible explanation for the increased cercopid nymph distribution around an ant mound is that it is triggered by high populations of honeydew-producing Homoptera.

Aphid-tents are constructed from both rainwater, spittle, and possibly other moisture droplets as well, but spittle may be a better adhesive. The large surface area of an air-filled spittlemass allows for construction of a tent that can house more Homoptera since particles placed on the spittle will have a natural cavity. Tents constructed from water on the other hand, tended to adhere closely to the stem (laboratory observations). Spittle is also longer lasting than rainwater in the field due to the glandular additives in the excreta. Lastly, a large difference in energy output is realized between carrying a rainwater-soaked particle to an aphid feeding site, and carrying up a dry particle to be placed onto an already wet mass.

\section{SUMMARY}

The interaction of prairie ants and meadow spittlebugs was investigated in the field and the laboratory. Ants are predators of spittlebug nymphs and construct aphid-tents using the spittle. This is the first account of ant predation on spittlebugs and spittle use in aphid-tents. Spittlebug nymph distribution appears to be influenced by the distribution of honeydew-producing homopterans. Spittle is an especially good building material since it helps to form a natural cavity when layered with soil, persists for a long time and requires an ant to carry a dry (as opposed to wet) soil particle to the site of construction.

\section{ACKNOWLEDGMENTS}

Funding sources supporting this research are as follows: Hatch grant \#2588; Roger Tory Peterson Institute of Natural History; 
Friends of the Arboretum, University of Wisconsin Arboretum; and the College of Agriculture and Life Sciences, University of Wisconsin-Madison.

\section{Literature Cited}

Akre, R. D., W. B. Garnett, J. F. MacDonald and A. Greene

1976 Behavior and colony development of Vespula pensylvanica and Vespula atropilosa. J. Kans. Entomol. Soc. 49: 63-84.

Buckton, G. B.

1890 Monograph of the British Cicadae or Tettigiidae. London.

Carroll, C. R., AND D. H. Janzen

1973 Ecology of foraging by ants. Annu. Rev. Ecol. Syst. 4: 231-257.

CeCIL, R.

1930 The alimentary canal of Philaenus leucophthalmus L. Ohio J. Sci. 30: 125-127.

Guilbeau, B. H.

1908 The origin and formation of the froth in spittle insects. Amer. Nat. 42: 783-789.

Henderson, G., R. O. Wagner, and R. L. Jeanne

1989 Colony longevity and mound growth in a prairie ant. Psyche 96: 257-268.

HoFFMAN, G. D.

1983 Plant architectural barriers to feeding site selection by the meadow spittlebug, Philaenus spumarius (L.). M.S. thesis. Oregon State Univ.

Hoffman, G. D. AND P. B. McEvoy

1986 Mechanical limitations on feeding by meadow spittlebugs Philaenus spumarius (Homoptera: Cercopidae) on wild and cultivated host plants. Ecol. Entomol. 11: 415-426.

HORSFIELD, D.

1978 Evidence for xylem feeding by Philaenus spumarius (L.) (Homoptera: Cercopidae). Entomologia Exper. Appl. 24: 95-99.

JONES, C. R.

1929 Ants and their relation to aphids. Bulletin 341, Colorado Exp. Sta., Fort Collins, $\mathrm{CO}$.

LICENT, E.

1912 Recherches d'anatomie et de physiologie comparées sur le tube digestif des Homoptères supérieurs. La Cellule 28: 1-161.

McEvoy, P. B.

1977 Adaptive significance of clumped dispersion in a tree hopper, Publilia concava (Homoptera:Membracidae). Ph.D. Thesis, Cornell University, Ithaca, NY.

McEvoy, P. B.

1986 Niche partitioning in spittlebugs (Homoptera: Cercopidae) sharing shelters on host plants. Ecology 67: 465-478. 
Pate, J. S.

1976 Nutrients and metabolites of fluids recovered from xylem and phloem: significance in relation to long-distance transport in plants. In: Transport processes in plants. Wardlaw, I. F., J. B. Passiour (eds). Academic Press, New York.

Pate, J. S.

1980 Transport and partitioning in nitrogenous solutes. Annu. Rev. Plant Pathol. 31: 313-340.

Stopes, M., AND C. G. HewitT

1909 The tent building habit of the ant Lasius niger Linn. in Japan. Nature 80: 2063.

WAY, M. J.

1963 Mutualisms between ants and honeydew-producing Homoptera. Ann. Rev. Entomol. 8: 307-344.

WEAVER, C. R., AND D. R. KING

1954 Meadow spittlebug. Research Bulletin 741. Ohio Agri. Exp. St. Wooster.

WHEELER, W. M.

1910 Ants, their structure, development and behavior. Columbia Univ. Press, New York.

WHITTAKER, J. B.

1970 Cercopid spittle as a microhabitat. Oikos 21: 59-64.

WIEGERT, R. G.

1964 The ingestion of xylem sap by meadow spittlebugs Philaenus spumarius (L.). Amer. Midl. Nat. 71: 422-428.

WILSON, H. A., AND C. K. DoRSEY

1957 Studies on the composition and microbiology of insect spittle. Ann. Entomol. Soc. Am. 50: 399-406.

ZAJAC, M. A., AND M. C. WILSON

1984 The effects of nymphal feeding by the meadow spittlebug, Philaenus spumarius (L.) on strawberry yield and quality. Crop Prot. 3: 167-175. 

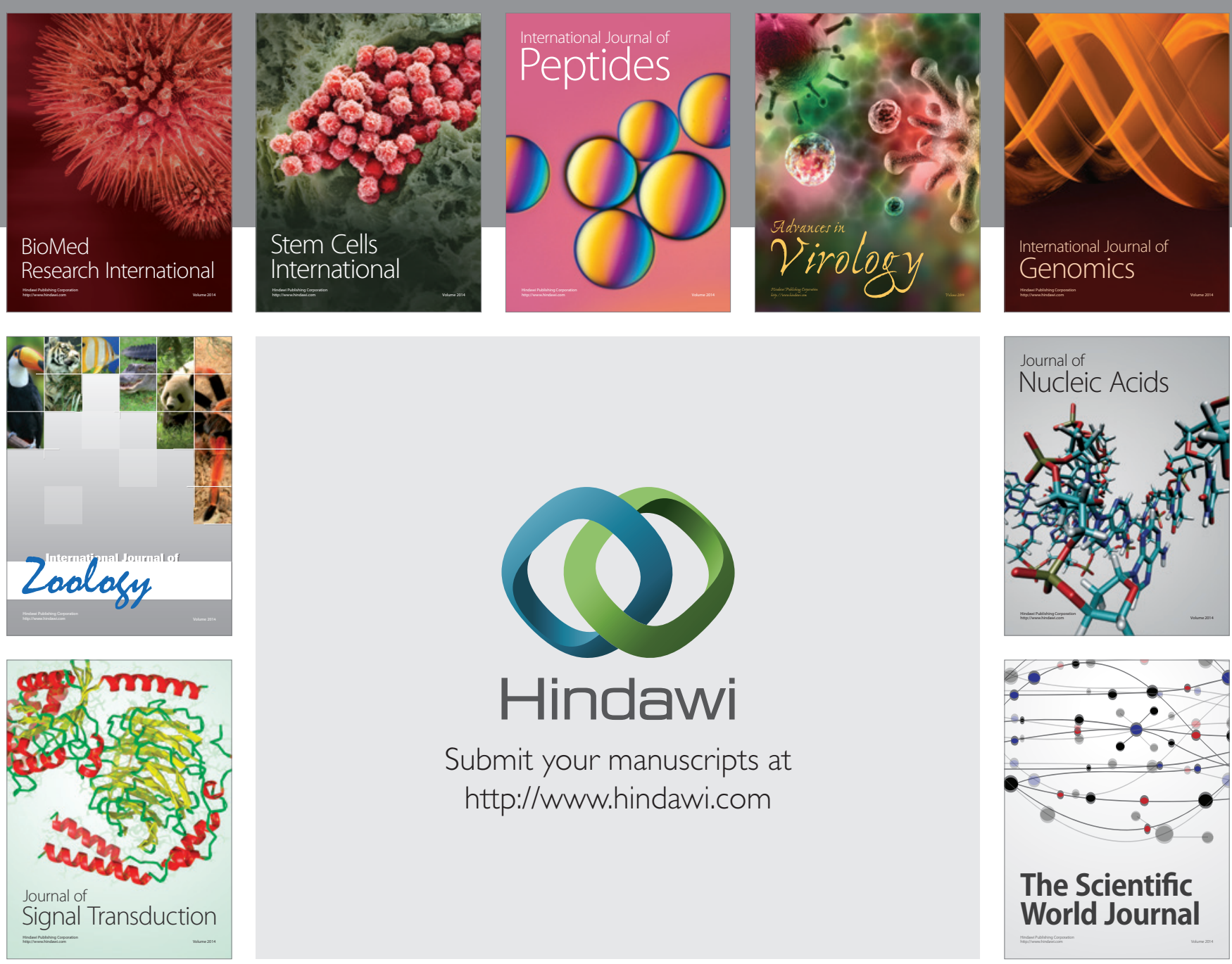

Submit your manuscripts at

http://www.hindawi.com
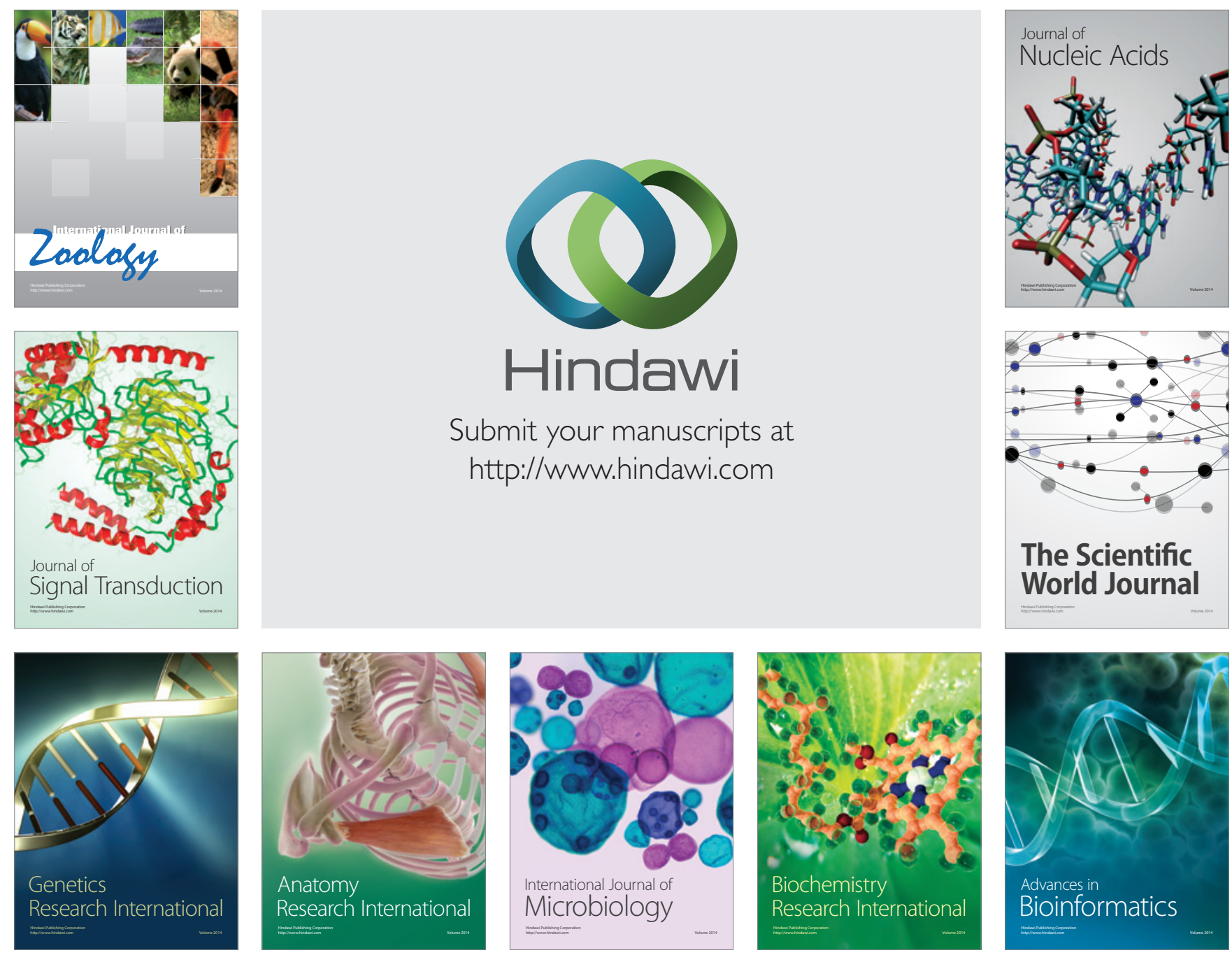

The Scientific World Journal
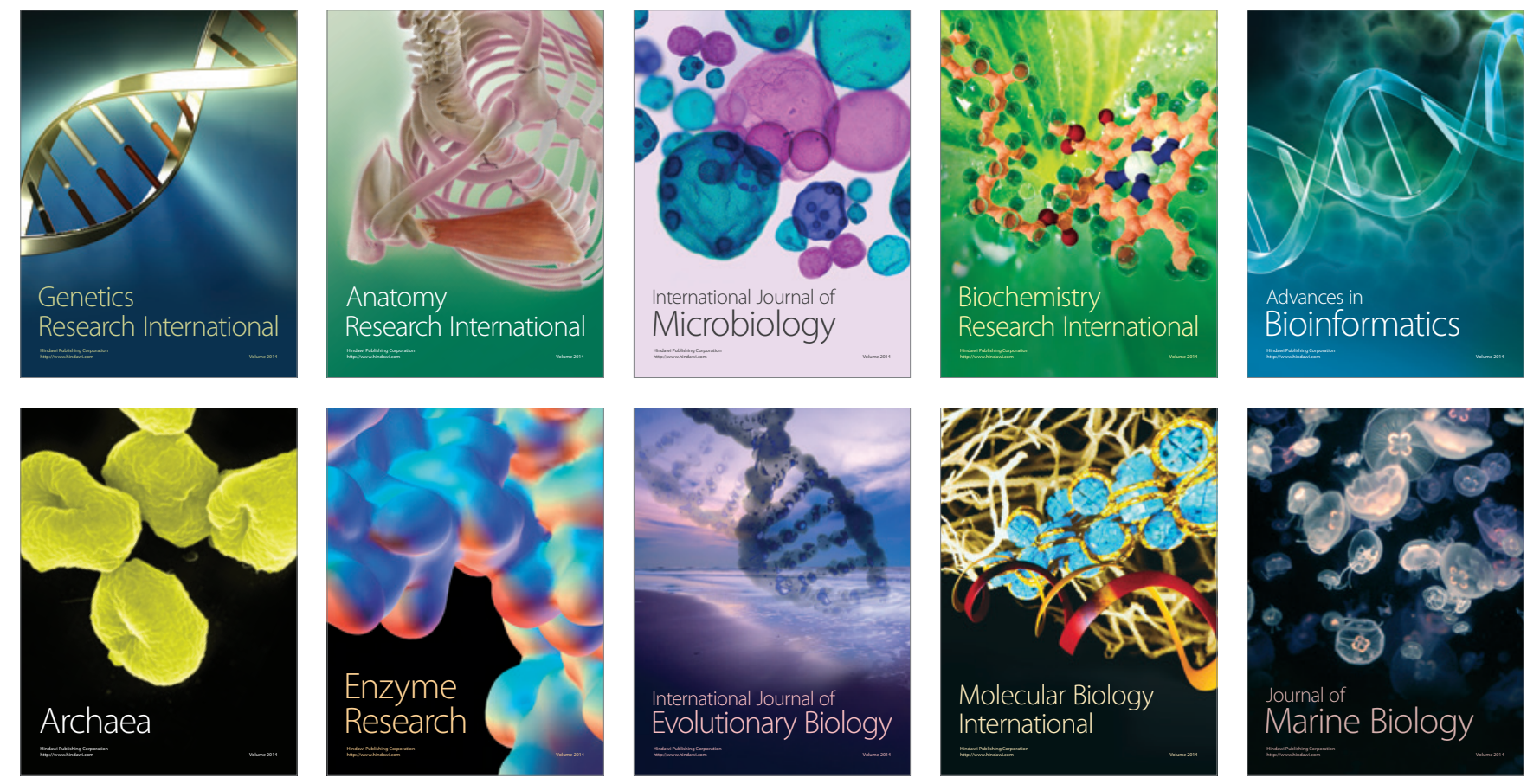